\title{
Prevalence of radix entomolaris in the mandibular molar teeth in Kashmiri population
}

\author{
Mohd Sajad $^{1, *}$, Ajmal Mir², Sameena Tabassum ${ }^{3}$, Aamir Rashid Purra ${ }^{4}$, Riyaz Farooq \\ ${ }^{1-3}$ Senior Resident, ${ }^{4}$ Associate Professor, ${ }^{5}$ Professor and HOD, Dept. of Conservative Dentistry and Endodontics, \\ Government Dental College and Hospital, Shireen Bagh, Srinagar, India
}

*Corresponding Author:

Email: drmohdsajad1986@gmail.com

\begin{abstract}
Introduction: An awareness and understanding of the presence of unusual root canal tooth morphology and its possible variations is valuable for successful endodontic treatment.

Objective: The objective of this study was to see the prevalence of Radix Entomolaris in population of Kashmir using radiographs.

Materials and Method: A total of 100 patients were included in the study and digital radiographs (RVG) were taken for their mandibular 1st permanent molars bilaterally. These radiographs were evaluated for presence of radix entomolaris and its correlation between the genders.

Results: The overall prevalence of individuals with radix entomolaris was $24 \%$. The incidence was $75 \%$ for unilateral whereas $25 \%$ for bilateral.

Conclusion: Presence of radix entomolaris in high proportion of Kashmiri population needs careful clinical and radiologic evaluation to ensure high long term success of endodontic treatment of permanent molars.
\end{abstract}

Keywords: Radix entomolaris, Prevalence, Digital radiograph, Root canal treatment

\section{Introduction}

Cleaning and shaping refers to the removal of all organic substrate from the root canal system and the development of a purposeful form within each canal for the reception of a dense and permanent filling. So, shaping implies the development of a unique shape for each root canal directly related to the length, position and curvature of the root. The goal of instrumentation is to produce a continuously tapering funnel from the root apex to the coronal access cavity. ${ }^{1}$

An awareness and understanding of the presence of unusual root canal tooth morphology and its possible variations is fundamental because the no treatment of one canal can lead to endodontic treatment failure. ${ }^{2}$

Permanent mandibular first molars usually have two roots mesial and distal and three root canals, but variations in the number of roots and in canal morphology are not uncommon. ${ }^{3}$ The additional third root, (i.e. the supernumerary root) in permanent mandibular first molar variants that have three roots is typically distributed lingually. This was first described by Carabelli in $1844^{4}$ and was termed radix entomolaris (RE) by Bolk in 1915. ${ }^{5}$ Similarly an additional root at the mesiobuccal side of the mandibular molar is called the radix paramolaris (RP). A $\mathrm{RE}$ can be found on the first, second and third mandibular molar, occurring least frequently on the second molar. Incidence of bilateral occurrence of RE varies between 50 to $67 \%$. $^{6}$

The extensive study of endodontic literature revealed that the prevalence of RE has a genetic and ethnic predilection and ranges from $0-33.1 \%$. The prevalence of $\mathrm{RE}$ is said to be highest among the population of Asian and Mongolian origin. Radix entomolaris is not very common in African, Eurasian, Caucasian population. ${ }^{7,8}$

There is genetic variation in number of roots and root canals in various individuals based upon race and ethnicity. This is why a clinician should identify all the variations before procedure so as to result in successful endodontic treatment. ${ }^{9}$ Therefore, aim of the present study was to evaluate the prevalence of radix entomolaris in Kashmiri population.

\section{Materials and Methods}

Bilateral radiographs of mandibular 1st permanent molars was done in 100 patients (76 males and 24 females) who visited the Department of Conservative Dentistry \& Endodontics after taking informed consent and selected randomly. The patients were of Kashmiri origin and were aged between 15-50 years. The radiographs were evaluated by two endodontists for total incidence of radix entomolaris and their occurrence in different genders. They were also evaluated for their occurrence unilaterally and bilaterally. The result was analyzed statistically (Chi square test) with $\mathrm{p}<0.05$ considered statistically significant.

\section{Results}

After interpretation of bilateral radiographs of 100 patients (76 males and 24 females), 24 patients (8 males and 16 females) had radix entomolaris. The prevalence in males was $10.5 \%$ whereas in females it was $66 \%$. (Table $1)$. The difference in prevalence between genders was statistically significant $(\mathrm{p}=0.030)$. The prevalence of unilateral $\operatorname{RE}(75 \%)$ was higher than bilateral $\operatorname{RE}(25 \%)$ (Table 2) 
Table 1: Radix Entomolaris in the mandibular molar teeth of Kashmiri population

\begin{tabular}{|l|c|c|c|}
\hline $\begin{array}{c}\text { Gender of patient } \\
\text { examined }\end{array}$ & $\begin{array}{c}\text { Number of patients } \\
\text { examined }\end{array}$ & $\begin{array}{c}\text { Patients with radix } \\
\text { entomolaris }\end{array}$ & Percentage \\
\hline Male & 76 & 8 & $10.5 \%$ \\
\hline Female & 24 & 16 & $66 \%$ \\
\hline Total & 100 & 24 & $24 \%$ \\
\hline
\end{tabular}

Table 2: Patients with radix entomolaris unilaterally and bilaterally according to gender

\begin{tabular}{|l|c|c|c|c|}
\hline & Male & Female & Total & $\begin{array}{c}\text { Percentage of } \\
\text { patients with radix } \\
\text { entomolaris }\end{array}$ \\
\hline $\begin{array}{l}\text { Total number of } \\
\text { patients }\end{array}$ & 76 & 24 & 100 & $24 \%$ \\
\hline $\begin{array}{l}\text { Unilateral radix } \\
\text { entomolaris radix }\end{array}$ & 6 & 12 & 18 & $75 \%$ \\
\hline $\begin{array}{l}\text { Bilateral } \\
\text { entomolaris }\end{array}$ & 4 & 6 & $25 \%$ \\
\hline
\end{tabular}

\section{Discussion}

The clinician must have thorough knowledge and skills for management of radix entomolaris to get the successful endodontic outcome. Radix entomolaris is one of the major variants observed in human permanent mandibular molars and failure to recognize this variant may jeopardize the prognosis of root canal therapy. ${ }^{10}$ Studies have shown that a large number of general dentists failed to appreciate this anatomic variant especially in mandibular molars. ${ }^{11,12}$

The reason for the formation of this extra root is still not clear. This can be attributed to some external factors during tooth formation or due to reappearance of a trait after many generations known as atavism. The morphology of the extra root is variable which can present as a full length root or a root with smaller size and different shape. ${ }^{13}$

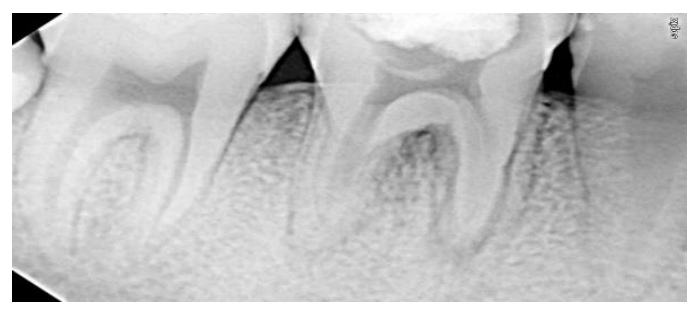

Fig 1: Intraoral periapical radiograph taken at 90 degree vertical angulation



Fig. 2: Intraoral periapical radiograph taken at 30 degree mesial angulation
De Moor et $\mathrm{al}^{6}$ stated that it is important to find all the roots of the mandibular first molars because of the presence of third root in some cases. So, it is convenient to do the x-rays from different horizontal angulations so as to find out the third root even in cases of superimposition and that would also help to identify anatomy of chamber and root canal. ${ }^{14}$

Radix entomolaris is a common finding in Asian/Mongolian populations, where up to $30 \%$ of mandibular molar teeth can show additional roots. In our study, after interpretation of bilateral radiographs of 100 patients (76 males and 24 females), 24 patients ( 8 males and 16 females) had radix entomolaris. So, total prevalence of radix entomolaris in Kashmiri population which is in the north of the India was $24 \%$ in first molars is higher than reported rates in European or Caucasian populations where the prevalence is typically less than $2 \%{ }^{15-18}$ The prevalence of radix entomolaris unilaterally was $75 \%$ (18 out of 24 patients) and bilaterally $25 \%$ ( 6 out of 24 patients).

Successful endodontic treatment in a tooth with radix entomolaris requires detailed radiographic and clinical examination. That is why digital radiographs were taken because they involve less usage of $\mathrm{x}$-rays as well as images can be magnified so that most of radix entomolaris cases can be detected (Fig. 1). To avoid the missing of some cases due to superimposition, a second image was taken at 30 degree angulation towards mesial side (Fig. 2). ${ }^{19}$

Three-dimensional imaging techniques based on computed tomography (CT) and cone beam computed tomography (CBCT) are useful for visualizing or studying the true morphology of an RE in a noninvasive manner using less radiation. However, cost and access to them are said to be the limiting factors. ${ }^{8,20}$

\section{Conclusion}

The prevalence of radix entomolaris in the population of Kashmir region of Jammu and Kashmir 
was observed to be $24 \%$ in our study which is higher than other population. The higher prevalence of radix entomolaris in Kashmiri population has a very important role in dentistry specially endodontics. Therefore, the clinicians should be well aware of this fact and should have knowledge about their prevalence and take every possible measure using the advanced diagnostic and imaging modalities to avoid any endodontic failure leading to high rate of treatment success and patient satisfaction.

\section{References}

1. Schilder H. Cleaning and shaping the root canal. Dent Clin North Am 1974;18:269-96.

2. Barbizam VB. Unusual anatomy of permanent maxillary molars. J Endod 2004;30:668-71.

3. Vertucci FJ. Root canal morphology and its relationship to endodontic procedures. Endod Topics 2005;10:3-29.

4. Carabelli G. Systematisches Handbuch der Zahnheikunde. 2nd ed. Vienna: Braumuller and Seidel. 1844:144.

5. Bolk L, Bemerkungen L. Morphology of mandibular molars. J Endod 1915;17:605-10.

6. De Moor R, Deroose C, Calberson F. The radix entomolaris in mandibular first molars: an endodontic challenge. Int Endod J 2004;37(11):789-99.

7. Garg AK, Tewari RK, Kumar A, Hashmi SH, Agrawal N, Mishra SK, et al. Prevalence of three-rooted mandibular permanent first molars among the Indian Population. J Endod 2010;36:1302-6.

8. Abella F, Patel S, Duran-Sindreu F, Mercade M, Roig M. Mandibular first molars with disto-lingual roots: Review and clinical management. Int Endod J 2012;45:963-78.

9. Mukhaimer Raed, Azizi Zafer. Incidence of Radix Entomolaris in Mandibular First Molars in Palestinian Population: A Clinical Investigation: Int Scholarly Res Notices Vol. 2014, Article ID 405601, 5 pages, 2014.

10. Ballullaya SV, Vemuri S, Kumar PR. Variable permanent mandibular first molar: Review of literature. J Conserv Dent 2013; 16: 99-110.

11. Slaus G, Bottenberg P. A survey of endodontic practice amongst Flemish dentists. Int Endod J. 2002;35:759-67.

12. Christie WH, Thompson GK The importance of endodontic access in locating maxillary and mandibular molar canals. J Canadian Dental Asso 1994;60:527-32.

13. Bains R, Bains VK, Loomba K, Loomba A. Prevalence of radix entomolaris and fused roots in mandibular permanent molars of a North Indian population: A hospital-based retrospective radiographic study. Ind J Oral Sci 2016;7(1):19-23.

14. Dube M, Trivedi P,Pandya M, Kumari M Incidence of Radix Entomolaris in the Indian Population - An In-vitro and In-vivo Analysis. J Int Oral Health 2011;3(5):35-45.

15. Calberson FL, De Moor RJ, Deroose CA. The radix entomolaris and paramolaris: clinical approach in endodontics. J Endod 2007;33(1):58-63.

16. Souza-Flamini LE., Leoni GB, Chaves JFM, Versiani MA, Cruz-Filho AM, Pécora JD, et al. The radix entomolaris and paramolaris: a micro-computed tomographic study of 3-rooted mandibular first molars. J Endod 2014;40(10):1616-21.

17. Tu MG, Tsai CC, Jou MJ, Chen WL, Chang YF, Chen SY, et al. Prevalence of three-rooted mandibular first molars among taiwanese individuals. J Endod 2007;33(10):1163-6.
18. Irodi S, Farook AZ. Three rooted mandibular molar; radix entomolaris and paramolaris. Int J Dental Clinics 2011;3:102-4.

19. Bharti R, Arya D, Saumyendra VS, Kulwinder KW, Tikku AP. Prevalence of radix entomolaris in Indian population. Ind J Stomatol 2011;(2)3:165-67.

20. Tu MG, Huang HL, Hsue SS, Hsu JT, Chen SY, Jou MJ, et al. Detection of permanent three-rooted mandibular first molar by cone-beam computed tomography imaging in Taiwanese individuals. J Endod 2009;35:503-7. 